\title{
Chromosomal instability, aneuploidy, and cancer
}

\author{
Samuel F. Bakhoum ${ }^{1,2 *}$ and Charles Swanton ${ }^{3,4} *$ \\ 1 Department of Internal Medicine, Mount Auburn Hospital, Cambridge, MA, USA \\ 2 Harvard Medical School, Boston, MA, USA \\ ${ }^{3}$ Cancer Research UK London Research Institute, London, UK \\ ${ }^{4}$ University College London Cancer Institute, London, UK \\ *Correspondence: samuel.f.bakhoum.dm@dartmouth.edu; charles.swanton@cancer.org.uk \\ Edited by: \\ Paolo Pinton, University of Ferrara, Italy \\ Reviewed by: \\ Frank Kruyt, University Medical Center Groningen, Netherlands
}

Keywords: chromosomal instability, aneuploidy, anaphase, chromatin, mitosis, spindle, microtubules, centrosomes

The link between aneuploidy and cancer has been recognized over a century ago (1). Abnormalities in chromosome copy numbers arise from persistent errors in chromosome segregation during cell division, a process known as chromosomal instability (CIN) (2). CIN is a principal contributor to genetic heterogeneity in cancer (3) and is an important determinant of clinical prognosis and therapeutic resistance $(4,5)$. Over the past two decades, our understanding of the mechanisms that lead to CIN as well as our appreciation of its consequences on cellular viability and tumor evolution have grown considerably $(4,6)$. So has our recognition of the multitude of questions that remain unanswered.

The papers in this Research Topic broadly address recent advances in our understanding of CIN in cancer. They also illustrate the diverse experimental approaches and model organisms used in studying genomic instability. This topic is divided into two major categories: the first five papers address the genesis of $\mathrm{CIN}$ in cancer by summarizing the cell biological mechanisms that underlie chromosome missegregation. They also venture into the poorly understood area of the genetic basis of CIN, while developing an experimental model system amenable to high-throughput genetic analysis. The remaining papers address the consequences of imbalance in chromosome number on the cellular fitness and adaptation.

Multiple mechanisms have been shown to lead to CIN - in its numerical and structural forms. They include defects in the spindle assembly checkpoint (7), sister chromatid cohesion (8), the regulation of microtubule attachments to chromosomes at kinetochores $(9,10)$, centrosome duplication $(11,12)$, telomere maintenance (13), and pre-mitotic replication stress (14). Herein, German Pihan (15) reviews the regulation of the centrosome duplication cycle and how it is intricately synchronized with the cell division cycle. The complexity of this regulatory network might explain pervasiveness of centrosome dysfunction in human tumors, but it also provides multiple attractive pharmacological targets that have the potential to induce mitotic catastrophe. Yokoyama and Gruss (16) further discuss how chromosomes take on part of the responsibility to ensure the fidelity of their own segregation. Chromatin-associated factors - beyond the Ran GTPase - have now been shown necessary for a properly functioning mitotic spindle. Interestingly, many of these factors localize to the Nuclear Pore Complex (NPC), highlighting an incipient spatiotemporal relationship between the interphase nuclear structure and the mitotic spindle (17). Thus the process of faithful chromosome segregation starts well before the onset of mitosis.

While many of the cellular events that underlie CIN have now been uncovered, the genetic basis of chromosome missegregation and aneuploidy remains elusive. A growing number of genetic perturbations have been shown capable of inducing CIN in otherwise normal mammalian cell lines (6). Yet, it remains unknown whether these experimental conditions mimic naturally occurring genetic events that lead to CIN during tumor progression. Further complicating this matter is the self-propagating nature of CIN (18), which can mask initial instigating genetic triggers. Herein, Rao and Yamada (19) review the linear progression model of colon carcinogenesis from adenoma to carcinoma. They discuss how many of the sequential genetic events that occur during carcinogenesis have the potential to compromise the fidelity of chromosome segregation. More generally, Orr and Compton (20) discuss the intimate relationship governing CIN and known oncogenic pathways. Given what we now know, they argue that almost every major oncogenic pathway can be implicated in some manner in the genesis of CIN. Yet this relationship is almost certainly bidirectional as chromosome missegregation has been shown to generate downstream structural chromosomal damage, which can in turn independently activate oncogenic pathways (2123). This complex relationship highlights the need for appropriate genetic models to better understand CIN. To this end, Salemi et al. (24) develop a chromosome segregation error correction assay, using the Drosophila melanogaster (Dm) S2 cells, that is amenable to high-throughput genetic screening. They substitute the Dm kinesin-5 protein, Klp61F, with its human ortholog, Eg5, thus acquiring the ability to purposely induce errors in microtubule attachments to chromosomes and subsequent chromosome missegregation through transient exposure to a small molecule inhibitor of Eg5 (25). These attachment errors occur in both normal and tumor cells alike (26), although cancer cells have been shown less efficient at correcting these errors (9). In this system, it would be feasible to screen for genes whose functions are 
to modulate the correction of microtubule attachment to chromosomes with the caveat that microtubule-associated proteins, particularly the kinesin family, may at times exhibit convergent evolution $(27,28)$ thus limiting direct comparative genetic analysis between Dm and humans.

The second part of this Research Topic addresses the consequences of CIN on cellular fitness in the context of tumor evolution. Roschke and Rozenblum (29) explore how CIN is tightly interconnected to other aspects of tumorigenesis such as DNA damage, loss of tumor suppressor genes, and gain of oncogenes. Importantly, they attempt to consolidate an apparent paradox in the field whereby the widespread prevalence of CIN in cancer stands in contrast to evidence showing that aneuploidy induces a proteotoxic stress response and reduces cellular fitness (30). They discuss the various pathways, which tumor cells utilize to cope with the cellular stressors involved with chromosome missegregation and they propose that tumor cells may balance the ability to rapidly proliferate with the need to generate sufficient diversity required for adaptation. One of the important adaptation mechanisms is the loss of the $p 53$ tumor suppressor pathway that normally limits the proliferation of aneuploid and tetraploid cells $(18,31)$. Although in this issue, Ohshima and Seyama (32) devise a method to derive tetraploid cells that appear to have an intact $p 53 / p 21$ signaling pathway that adequately responds to DNA damage, strongly suggesting the existence of alternative pathways that may confer tolerance to non-diploid karyotypes. Finally, Nicholson and Cimini (33) discuss the uni-directionality of CIN and aneuploidy. In most cases, it appears that once diploid cells become aneuploid, they also appear to become chromosomally stable. This positive feed-forward loop linking aneuploidy and CIN would constantly generate karyotypic heterogeneity that is shaped by natural selection. From this, the authors discuss how broad karyotypic patterns emerge that may shed light on defining karyotypic changes during tumor evolution.

\section{REFERENCES}

1. Boveri T. Über mehrpolige Mitosen als Mittel zur Analyse des Zellkerns. Stuber (1903).

2. Lengauer C, Kinzler KW, Vogelstein B. Genetic instabilities in human cancers. Nature (1998) 396:643-9. doi:10.1038/25292

3. Burrell RA, McGranahan N, Bartek J, Swanton C. The causes and consequences of genetic heterogeneity in cancer evolution. Nature (2013) 501:338-45. doi:10.1038/nature 12625

4. Bakhoum SF, Compton DA. Chromosomal instability and cancer: a complex relationship with therapeutic potential. J Clin Invest (2012) 122:1138-43. doi:10.1172/JCI59954

5. Lee AJX, Endesfelder D, Rowan AJ, Walther A, Birkbak NJ, Futreal PA, et al. Chromosomal instability confers intrinsic multidrug resistance. Cancer Res (2011) 71:1858-70. doi:10.1158/0008-5472.CAN-10-3604

6. Thompson SL, Bakhoum SF, Compton DA. Mechanisms of chromosomal instability. Curr Biol (2010) 20:R285-95. doi:10.1016/j.cub.2010.01.034

7. Cahill DP, Lengauer C, Yu J, Riggins GJ, Willson JK, Markowitz SD, et al. Mutations of mitotic checkpoint genes in human cancers. Nature (1998) 392:300-3. doi: $10.1038 / 32688$

8. Zhang N, Ge G, Meyer R, Sethi S, Basu D, Pradhan S, et al. Overexpression of Separase induces aneuploidy and mammary tumorigenesis. Proc Natl Acad Sci USA (2008) 105:13033-8. doi:10.1073/pnas.0801610105

9. Bakhoum SF, Genovese G, Compton DA. Deviant kinetochore microtubule dynamics underlie chromosomal instability. Curr Biol (2009) 19:1937-42. doi:10.1016/j.cub.2009.09.055
10. Bakhoum SF, Thompson SL, Manning AL, Compton DA. Genome stability is ensured by temporal control of kinetochore-microtubule dynamics. Nat Cell Biol (2009) 11:27-35. doi:10.1038/ncb1809

11. Ganem NJ, Godinho SA, Pellman D. A mechanism linking extra centrosomes to chromosomal instability. Nature (2009) 460:278-82. doi:10.1038/nature08136

12. Silk AD, Zasadil LM, Holland AJ, Vitre B, Cleveland DW, Weaver BA. Chromosome missegregation rate predicts whether aneuploidy will promote or suppress tumors. Proc Natl Acad Sci USA (2013) 110:E4134-41. doi:10.1073/pnas. 1317042110

13. Davoli T, Denchi EL, de Lange T. Persistent telomere damage induces bypass of mitosis and tetraploidy. Cell (2010) 141:81-93. doi:10.1016/j.cell.2010. 01.031

14. Burrell RA, McClelland SE, Endesfelder D, Groth P, Weller M-C, Shaikh N, et al. Replication stress links structural and numerical cancer chromosomal instability. Nature (2013) 494:492-6. doi:10.1038/nature11935

15. Pihan GA. Centrosome dysfunction contributes to chromosome instability, chromoanagenesis, and genome reprograming in cancer. Front Oncol (2013) 3:277. doi:10.3389/fonc.2013.00277

16. Yokoyama H, Gruss OJ. New mitotic regulators released from chromatin. Front Oncol (2013) 3:308. doi:10.3389/fonc.2013.00308

17. Rodriguez-Bravo V, Maciejowski J, Corona J, Buch HK, Collin P, Kanemaki MT, et al. Nuclear pores protect genome integrity by assembling a premitotic and mad1-dependent anaphase inhibitor. Cell (2014) 156:1017-31. doi:10.1016/j. cell.2014.01.010

18. Thompson SL, Compton DA. Proliferation of aneuploid human cells is limited by a p53-dependent mechanism. J Cell Biol (2010) 188:369-81. doi:10.1083/jcb. 200905057

19. Rao CV, Yamada HY. Genomic instability and colon carcinogenesis: from the perspective of genes. Front Oncol (2013) 3:130. doi:10.3389/fonc.2013.00130

20. Orr B, Compton DA. A double-edged sword: how oncogenes and tumor suppressor genes can contribute to chromosomal instability. Front Oncol (2013) 3:164. doi:10.3389/fonc.2013.00164

21. Stephens PJ, Greenman CD, Fu B, Yang F, Bignell GR, Mudie LJ, et al. Massive genomic rearrangement acquired in a single catastrophic event during cancer development. Cell (2011) 144:27-40. doi:10.1016/j.cell.2010.11.055

22. Crasta KK, Ganem NJN, Dagher RR, Lantermann ABA, Ivanova EVE, Pan YY, et al. DNA breaks and chromosome pulverization from errors in mitosis. Nature (2012) 482:53-8. doi:10.1038/nature10802

23. Yates LR, Campbell PJ. Evolution of the cancer genome. Nat Rev Genet (2012) 13:795-806. doi:10.1038/nrg3317

24. Salemi JD, McGilvray PT, Maresca TJ. Development of a Drosophila cell-based error correction assay. Front Oncol (2013) 3:187. doi:10.3389/fonc.2013.00187

25. Lampson MA, Renduchitala K, Khodjakov A, Kapoor TM. Correcting improper chromosome-spindle attachments during cell division. Nat Cell Biol (2004) 6:232-7. doi: $10.1038 /$ ncb 1102

26. Cimini DD, Moree B, Canman JC, Salmon ED. Merotelic kinetochore orientation occurs frequently during early mitosis in mammalian tissue cells and error correction is achieved by two different mechanisms. J Cell Sci (2003) 116:4213-25. doi: $10.1242 /$ jcs.00716

27. Wickstead B, Gull K. A "holistic" kinesin phylogeny reveals new kinesin families and predicts protein functions. Mol Biol Cell (2006) 17:1734-43. doi:10.1091/mbc.E05-11-1090

28. Manning AL, Ganem NJ, Bakhoum SF, Wagenbach M, Wordeman L, Compton DA. The kinesin-13 proteins Kif2a, Kif2b, and Kif2c/MCAK have distinct roles during mitosis in human cells. Mol Biol Cell (2007) 18:2970-9. doi:10.1091/mbc.E07-02-0110

29. Roschke AV, Rozenblum E. Multi-layered cancer chromosomal instability phenotype. Front Oncol (2013) 3:302. doi:10.3389/fonc.2013.00302

30. Williams BR, Prabhu VR, Hunter KE, Glazier CM, Whittaker CA, Housman DE, et al. Aneuploidy affects proliferation and spontaneous immortalization in mammalian cells. Science (2008) 322:703-9. doi:10.1126/science.1160058

31. Fujiwara T, Bandi M, Nitta M, Ivanova EV, Bronson RT, Pellman D. Cytokinesis failure generating tetraploids promotes tumorigenesis in p53-null cells. Nature (2005) 437:1043-7. doi:10.1038/nature04217

32. Ohshima S, Seyama A. Establishment of proliferative tetraploid cells from normal human fibroblasts. Front Oncol (2013) 3:198. doi:10.3389/fonc.2013.00198

33. Nicholson JM, Cimini D. Cancer karyotypes: survival of the fittest. Front Oncol (2013) 3:148. doi:10.3389/fonc.2013.00148 
Conflict of Interest Statement: The authors declare that the research was conducted in the absence of any commercial or financial relationships that could be construed as a potential conflict of interest.

Received: 01 May 2014; accepted: 06 June 2014; published online: 19 June 2014. Citation: Bakhoum SF and Swanton C (2014) Chromosomal instability, aneuploidy, and cancer. Front. Oncol. 4:161. doi: 10.3389/fonc.2014.00161
This article was submitted to Molecular and Cellular Oncology, a section of the journal Frontiers in Oncology.

Copyright (c) 2014 Bakhoum and Swanton. This is an open-access article distributed under the terms of the Creative Commons Attribution License (CC BY). The use, distribution or reproduction in other forums is permitted, provided the original author(s) or licensor are credited and that the original publication in this journal is cited, in accordance with accepted academic practice. No use, distribution or reproduction is permitted which does not comply with these terms. 